\title{
Mechanism of Enhanced Dermal Permeation of 4-Cyanophenol and Methyl Paraben from Saturated Aqueous Solutions Containing Both Solutes
}

\author{
W.J. Romonchuk A.L. Bunge \\ Chemical Engineering Department, Colorado School of Mines, Golden, Colo., USA
}

\section{Key Words}

Dermal permeation - 4-Cyanophenol · Methyl paraben • Saturated aqueous solution - Thermodynamic activity • Enhancer $\cdot$ Stratum corneum uptake

\begin{abstract}
Dermal permeation through human epidermis and uptake into isolated human stratum corneum (SC) that was and was not delipidized were measured for 2 model compounds, 4cyanophenol (CP) and methyl paraben (MP), from saturated aqueous solutions containing 1 or both compounds. Because the solutions were in equilibrium with the pure $C P$ and $M P$, the thermodynamic activity of the compounds was constant. Compared with compounds that are known permeation enhancers, MP and CP would not normally be expected to act as enhancers. Nevertheless, when both compounds were present, the steady-state fluxes through the epidermis increased by factors of 5.2 and 2.6 for MP and CP, respectively. Within the variability of the measurements, this increase in MP flux is consistent with the 6.4-fold increase in the SC uptake, which occurs primarily into the nonlipid regions of the SC. In contrast, the 1.6-fold increase in CP uptake when MP is present is too small to explain the increase in $C P$ flux. These results suggest that $C P$ enhances the skin permeation of MP by primarily increasing the solubility of MP in the $\mathrm{SC}$, especially in the nonlipid regions, while MP increases the skin permeation of $C P$ by enhancing both the solubility and diffusivity of $\mathrm{CP}$ in the SC.

Copyright $\odot 2010$ S. Karger AG, Basel
\end{abstract}

\section{Introduction}

Dermal permeation of a single solute dissolved in water has been studied extensively using in vitro diffusion cell experiments. However, dermal permeation from aqueous solutions containing more than 1 solute has been studied rarely, despite its obvious practical importance. Lacking other information, one might anticipate that permeation of a given solute at the same concentration would be the same from solutions containing that solute alone or that solute mixed with others. For this to be true, at least 2 criteria must be satisfied: (1) the thermodynamic activity of the given solute in the solution is not changed by the presence of other solutes added to the solution, and (2) the properties of the stratum corneum (SC) in contact with the single-component solutions are the same as for the mixed-component solution. For many chemicals, the SC controls the rate of chemical permeation through the skin. Chemicals that change the properties of the SC to increase the chemical permeation of another compound are called enhancers, those that decrease permeation retarders [1].

Numerous studies have established the relationship between the thermodynamic activity of a solute in the solution and its skin permeation. Among the many examples are studies by Barry et al. [2, 3], Theewes et al. [4], and Twist and Zatz [5]. When solutes in a solution of 2 or more solutes interact with each other, then the thermodynamic activity in the multisolute solution will differ

\section{KARGER}

Fax +4161306 1234

E-Mail karger@karger.ch

www.karger.com (c) 2010 S. Karger AG, Basel

$1660-5527 / 10 / 0233-0152 \$ 26.00 / 0$

Accessible online at:

www.karger.com/spp
Professor Annette L. Bunge

Chemical Engineering Department, Colorado School of Mines

1500 Illinois Street

Golden, CO 80401 (USA)

Tel. +1 303273 3722, Fax +1 303273 3730, E-Mail abunge@ mines.edu 
from the single-solute solution at the same concentration. When this happens, to determine if the added chemicals enhance, retard or have no effect on solute permeation through the SC, either the thermodynamic activity of the permeating solute must be measured or the solutions must be prepared in a way that insures constant thermodynamic activity of the permeating solute. An example of the former approach is the study by Kurihara-Bergstrom et al. [6] in which the thermodynamic activity of a 1 weight percent alcohol (i.e. methanol, 1-butanol or 1-octanol) was measured in aqueous solutions of saline with varying amounts of dimethyl sulfoxide (DMSO). They showed that the steady-state permeation of the alcohol through the skin was proportional to the alcohol's thermodynamic activity in the solution provided the DMSO concentration did not exceed about 50 weight percent.

The approach of insuring constant thermodynamic activity is convenient for solutes that are solids at skin temperature with limited solubility in the solution. As long as the solutes do not interact to form a solid mixture, the saturated solutions of a given solute prepared alone or mixed with other saturated solutes will each be in equilibrium with their pure powder. In this case, the thermodynamic activity of each of the compounds will be the same in saturated solutions of 1 or more compounds. Even though the thermodynamic activity of a saturated solute is constant, the saturation concentration of a solute in a single- or multisolute solution will be different if it interacts with other solutes in the multisolute solution.

As mentioned previously, chemicals can alter the SC in ways that change permeation rates through it. The mechanisms for permeation enhancement include disrupting the structure of the intercellular lipid lamellae in the SC (e.g. oleic acid), altering the solvating properties of the SC as indicated by changes in partitioning (e.g. ethanol), interacting with the proteins in the corneocytes, and by extracting components from the SC (e.g. DMSO) [7]. The mechanisms for retarding permeation are less obvious. One example is the reduced permeation of several neat glycol alkyl ethers compared with their aqueous solutions, which may occur because the SC is desiccated by the neat liquids [8]. Significantly, to assess with certainty that a change in formulation causes enhancement or retardation requires that the thermodynamic activity of the solute in the solutions be known or held constant.

The rate at which solutes permeate through any nonporous membrane depends on the solubility of the chemical in the membrane as well as the diffusion rate through the membrane. Even if the diffusion rate is large, there can be no flux if there is no solubility, which is why poly- ethylene film, which has an extremely low water solubility, is an effective barrier to water even though the diffusivity within the film for a little molecule like water is almost certainly not small. The contribution of these 2 mechanisms, diffusivity and solubility, is evident in Fick's law, which is written here to describe the steady-state flux $\left(J_{s s}\right)$ through the SC, assuming it behaves as a pseudohomogeneous membrane:

$$
J_{s s}=\left(C_{e q, s c} h \rho_{s c}\right)\left(D / h^{2}\right)
$$

In this equation, $C_{e q, s c}$ is the concentration in the SC that is equilibrated with a donor solution given in units of milligrams of chemical per gram of dry SC, $h$ is the thickness of the hydrated SC, $D$ is the effective diffusion coefficient of the chemical in the SC and $\rho_{s c}$ is the density-type parameter required to convert the dry mass of SC to its hydrated volume (i.e. $\rho_{s c}$ is the dry mass of the SC per hydrated volume of SC). According to Vecchia and Bunge [9], $\rho_{s c}$ is most likely about $0.27 \mathrm{~g} / \mathrm{ml}$ (i.e. approximately $3.7 \mathrm{ml}$ of hydrated SC per gram of dry SC). If the donor solution is saturated, then $C_{e q, s c}$ is essentially the saturation limit for the chemical in the SC. The product of $C_{e q}$, ${ }_{s c}$ and $\rho_{s c}$ represents the equilibrium uptake (i.e. saturation) concentration per volume of hydrated $\mathrm{SC}$, and $\left(h C_{e q}\right.$, $\left.{ }_{s c} \rho_{s c}\right)$ is the saturated mass of chemical per area of the SC. The separate contributions of solubility and diffusion to the rate of chemical permeation through the SC are represented by $\left(h C_{e q, s c} \rho_{s c}\right)$ and $\left(D / h^{2}\right)$, respectively.

When the permeation of a solute through the SC is enhanced or retarded, the mechanism for the effect can be solubility, diffusion or a combination of the two. The primary mechanism can be deduced if the amount of solute uptake (i.e. $C_{e q, s c}$ ) and the rate of solute permeation (i.e. $J_{s s}$ ) from the same solutions are both measured. To illustrate this approach, we determined the permeation rates and solute uptake of 2 model compounds, 4-cyanophenol (CP) and methyl paraben (MP), which are shown in figure 1, from saturated aqueous solutions containing 1 or both compounds. Because the solutions are saturated, the thermodynamic activities of the compounds are constant, whether or not the other compound is present. Although these compounds would not normally be expected to act as permeation enhancers, the fluxes of MP and $\mathrm{CP}$ did increase in the presence of the other, as did their uptake. As shown below, CP increases the permeation of MP by primarily changing the solubility of MP in the SC, particularly in the fraction left after the lipids are extracted. In contrast, MP enhances the permeation of CP by increasing the diffusivity and also the solubility, which occurs equally in the lipid and nonlipid parts of the 
SC. Finally, we show that a similar analysis of recently reported measurements from saturated aqueous solutions of MP and 3 other parabens in the absence and presence of nicotinamide (NA), shown in figure 1, is useful for assessing the mechanism of enhanced or retarded permeation.

\section{Methods and Materials}

\section{Chemicals}

Reagent grade CP and MP were purchased from Aldrich (Milwaukee, Wisc., USA) and Sigma (St. Louis, Mo., USA), respectively. HPLC grade acetonitrile was from Pharmaco-Aaper (Brookfield, Conn., USA); methanol and chloroform, both HPLC grade, were from Mallinckrodt (Phillipsburg, N.J., USA). Water was deionized (DI) and polished with a Millipore Milli-Q water system (Bedford, Mass., USA). The receptor fluid in the diffusion cell experiments was $0.01 \mathrm{M}$ phosphate-buffered saline (PBS, from Sigma P-3813, $0.138 \mathrm{M} \mathrm{NaCl}$; $0.0027 \mathrm{M} \mathrm{KCl}$; $\mathrm{pH} 7.4$ at $25^{\circ} \mathrm{C}$ ), which was degassed by vacuum filtration through a $0.45-\mu \mathrm{m}$ pore size Nylaflo ${ }^{\circledR}$ nylon membrane filter (Pall Gelman Sciences, Ann Arbor, Mich., USA) to prevent bubbles in the receptor chamber and the flow lines. MP is susceptible to biodegradation. Therefore, solutions containing MP were treated with a small amount of chloroform (approximately $0.05-0.15 \mathrm{mg} / \mathrm{ml}$ ); the PBS receptor solutions also contained sodium azide $(0.02 \mathrm{mg} / \mathrm{ml})$ from Aldrich Chemical.

CP is a moderately lipophilic chemical (the logarithm of the octanol-water partition coefficient, $\log K_{\text {ow }}$ is 1.60 [10]) of small size (the molecular weight, $M W$, is 119) that is solid at skin temperature $\left(T_{m}=112^{\circ} \mathrm{C}[10]\right)$. Compared with $\mathrm{CP}$, MP is slightly larger, more lipophilic and melts at a higher temperature $(M W=$ $\left.152.1, \log K_{o w}=1.96, T_{m}=131^{\circ} \mathrm{C}[10]\right)$. Both CP and MP are readily soluble in water, but CP is more soluble. Although CP is a weak acid, calculations made using its $\mathrm{pK}_{\mathrm{a}}$ of 7.97 at $25^{\circ} \mathrm{C}$ [10] indicate it should be mostly undissociated. Assuming that MP and CP do not form a solid mixture, saturated solutions of $\mathrm{CP}$ and MP alone or together are in equilibrium with the pure powder of each chemical present. Thus, the thermodynamic activity of each of the compounds will be the same in saturated solutions of 1 and both compounds, although the saturation concentrations in these 2 solutions might be different.

\section{Skin and Membrane}

Split-thickness human skin (approximately $350 \mu \mathrm{m}$ thick) collected within $24 \mathrm{~h}$ postmortem was purchased from National Disease Research Interchange (Philadelphia, Pa., USA). Experiments were performed on skin from 2 subjects identified as L (back skin from a Caucasian female, aged 77 years) and Q (leg skin from a Caucasian male, aged 73 years). The skin was stored at approximately $-70^{\circ} \mathrm{C}$ until use. Prior to a permeability experiment, the skin was removed from the freezer, cut into pieces of about $1 \mathrm{~cm}^{2}$ and the epidermis separated from the dermis by heating for $60 \mathrm{~s}$ at $60^{\circ} \mathrm{C}$ [11]. Isolated SC was used in the uptake experiments. This was prepared by enzymatically digesting the dermis and viable epidermis from $1.5 \times 1.5 \mathrm{~cm}$ pieces of split-thickness skin in a $1 \%$ trypsin solution (from bovine pancreas, essentially salt free, 8.060

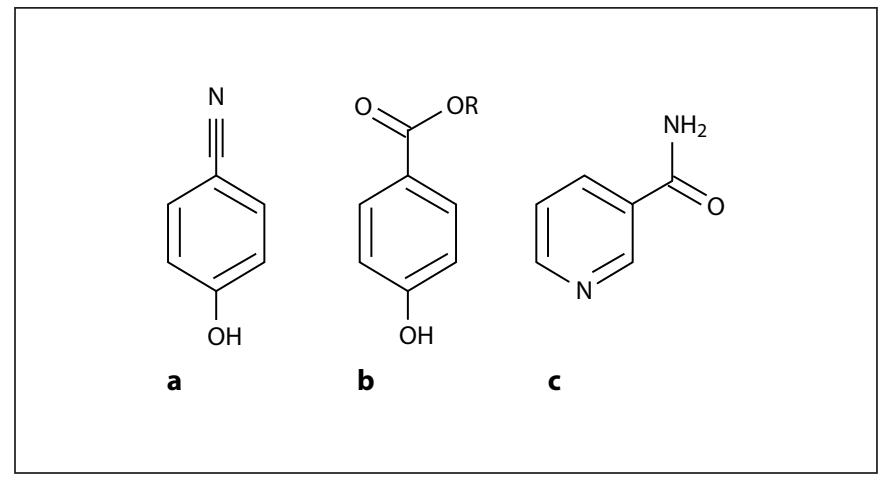

Fig. 1. a 4-cyanophenol. b R paraben. c Nicotinamide.

BAEE units/milligram solid and 9.060 BAEE units/milligram of protein, T-8915, Sigma) for approximately $36 \mathrm{~h}$ at $32^{\circ} \mathrm{C}$ as described elsewhere $[12,13]$. After the SC had been carefully peeled from the digested skin tissues, it was rinsed with distilled water, dried and stored in a desiccator for later use.

The silicone rubber membrane (SRM) from Samco Silicone Products (Nuneaton, Warwickshire, UK: product code 19T0.31000-60M1) had an average thickness of $359.8 \pm 2.8 \mu \mathrm{m}$ [14]. It was cut into circles to fit into the diffusion cells and rinsed thoroughly with DI water.

\section{Permeation Experiments}

The permeation of CP and MP, alone or in combination, through heat-separated skin was determined in vertical flowthrough Neoflon ${ }^{\mathrm{TM}}$ diffusion cells $(9 \mathrm{~mm}$, series 1 , in-line) from Permegear (Bethlehem, Pa., USA). The diffusion area of these cells is $0.64 \mathrm{~cm}^{2}$ and the volumes of the donor and receptor chambers are approximately 1.0 and $0.5 \mathrm{ml}$, respectively. The skin membrane was clamped into each of the 14 cells with SC facing the donor chamber. The receptor chambers were then filled with PBS, connected to a peristaltic pump (Ismatec, Cole Parmer Instrument Company, Chicago, Ill., USA) and the cells were placed onto 1 of 2 cell holders (Permegear), which accommodated 7 cells each. A short tube from the receptor chamber outlet directs the receptor fluid into a liquid scintillation vial positioned in a fraction collector (Retriever IV, ISCO Inc., Lincoln, Nebr., USA). The cells and collection system are contained in an environmental chamber in which temperature and humidity are controlled.

In all experiments, skin mounted in the diffusion cells with a receptor solution flowing at $0.6 \mathrm{ml} \cdot \mathrm{h}^{-1}$ was equilibrated overnight (approximately $12 \mathrm{~h}$ ) inside the environmental chamber set at $32^{\circ} \mathrm{C}$ and $50 \%$ relative humidity. After this, the donor chamber was filled with a saturated aqueous solution containing 1 or both compounds and the receptor solution flow rate adjusted to $6 \mathrm{ml}$. $\mathrm{h}^{-1}$. Excess chemical was added to the donor solution to ensure that it remained saturated during the entire exposure time. In a typical experimental run, the donor solution for 5 cells contained both MP and CP and the donor solutions for the remaining 9 cells were split between MP and CP alone. In some experiments, the skin of 1 or 2 cells leaked and the data were unusable. Receptor solution samples were collected hourly. The receptor solution flow rate to each cell was determined by averaging the solution 
weight of the samples collected over the time intervals ending in odd numbers (e.g. 1, 3, 5 h). The concentrations of CP and/or MP in the receptor fluid were determined by HPLC.

Measurement of CP and MP permeation through the SRM followed the same procedure as the skin experiments with only a few modifications. After loading the SRM into the cells, the donor chambers were filled with PBS and the systems equilibrated overnight at $32^{\circ} \mathrm{C}$ in the environmental chamber. In the morning the PBS was replaced with the selected donor solution, which was saturated with CP, MP or both. The receptor solutions were collected and weighed at 1-hour intervals for $8 \mathrm{~h}$.

\section{Uptake and Solubility Determinations}

Pieces of dry isolated SC were weighed (2-4 mg) using a semimicrogram balance (Mettler Toledo AX26DR Delta Range, Columbus, Ohio, USA) and then equilibrated in $5 \mathrm{ml}$ of saturated solution without particles of excess chemical that could adhere to the SC and confound the results. Stock saturated solutions of MP, $\mathrm{CP}$ or MP and CP were prepared by adding dialysis bags (Spectrapor, standard cellulose, cellulose dialysis tubing, molecular weight cutoff $=12,000-14,000$, Spectrum Laboratories, Los Angeles, Calif., USA) containing DI water with excess amounts of either MP or CP powder to approximately $250 \mathrm{ml}$ of DI water. Solutions with both MP and CP were prepared by adding 2 dialysis bags, each containing 1 chemical. Skin samples were equilibrated at $32^{\circ} \mathrm{C}$ in the solutions for at least $24 \mathrm{~h}$, after which the skin was rinsed quickly in DI water, and extracted for about $2 \mathrm{~h}$ in $5 \mathrm{ml}$ of DI water 3 times in succession. The concentrations of the extracts were determined by HPLC using appropriate dilutions and the amount of uptake per mass of dry SC calculated $\left(C_{s c, \text { eq }}\right)$. The concentration of chemical in the third extraction was always small.

The chemical concentrations in duplicate samples from the saturated stock solutions $\left(C_{s a t}\right)$ and in the solutions that had been equilibrated with the SC samples $\left(C_{e q}\right)$ were also determined by HPLC of the diluted samples. Because the solution in contact with the SC did not contain excess chemical, $C_{e q}$ could be reduced significantly compared with $C_{\text {sat }}$ if the chemical uptake into the SC was large enough. As a result, the measured equilibrium uptake, $C_{s c, e q}$, would be less than the uptake into the SC from the saturated solution $\left(C_{s c, s a t}\right)$. Consequently, if $C_{e q}$ was determined to be significantly different from $C_{s a t}$, then $C_{s c \text {, sat }}$ was estimated using equation (2):

$$
C_{s c, s a t}=C_{s c, e q}\left(C_{s a t} / C_{e q}\right)
$$

This should be a good estimate for $C_{s c \text {, sat }}$ provided that $C_{s a t}$ and $C_{e q}$ are not too different from each other. If $C_{s c, s a t}$ for $\mathrm{CP}$ or $\mathrm{MP}$ measured from solutions containing 1 or both compounds are not the same, then the properties of the SC, at least with respect to solubility, are changed by the presence of the other compound.

\section{Uptake into Delipidized SC}

To assess the contribution of the lipid and nonlipoidal components of the SC on uptake, a second series of experiments were conducted to compare the results for delipidized and untreated SC. Lipids from weighed pieces of dry isolated SC were extracted by soaking with gentle agitation for approximately $20 \mathrm{~h}$ in $10 \mathrm{ml}$ of 2:1 v:v chloroform:methanol. The SC was rinsed 3 times in fresh samples of the chloroform:methanol solution and placed on Teflon ${ }^{\circledR}$ sheets. The remaining solvent was removed by evaporation at room temperature for at least 3 days, after which the SC was weighed. The mass fraction (dry mass basis) of the lipids removed from the delipidized SC $\left(f_{\text {lip }}\right)$ was calculated from the change in sample weight.

Measurements of uptake into delipidized SC and untreated SC were made in a modification of the procedure described above. Experiments were conducted in PTFE (Teflon) equilibrium microdialyzers (Harvard Apparatus, Holliston, Mass., USA), which consist of 2 capped 0.5 -ml chambers separated by a porous nylon membrane (Nylaflo, Pall Life Sciences, $0.45 \mu \mathrm{m}$ pore size, $47 \mathrm{~mm}$ diameter), cut to fit the dialyzer with a size 10 cork borer. One chamber of the dialyzer was filled with excess chemical and solution saturated at $32^{\circ} \mathrm{C}$. The SC sample was added to the other chamber, which was filled with the same saturated solution without particles of chemical. The assembled dialyzers were incubated at $32^{\circ} \mathrm{C}$ for approximately $48 \mathrm{~h}$. After this, a $100-\mu \mathrm{l}$ sample was collected from the chamber with the SC and then diluted in $20 \mathrm{ml}$ of acetonitrile. The SC sample was removed and quickly rinsed 3 times in acetonitrile to remove adhering solution and then extracted into 10 or $20 \mathrm{ml}$ of acetonitrile for $8 \mathrm{~h}$ at room temperature. The SC was then extracted for about 16 and then $8 \mathrm{~h}$ in $3-\mathrm{ml} \mathrm{sam-}$ ples of acetonitrile. The concentrations of MP and/or CP in the extracts were determined by HPLC. Typically, the concentrations in the solution from the third extraction were 0 , and less than $10 \%$ of the chemical uptake was found in the second extraction. Each experiment consisted of 20 dialysis cells using the SC from a single subject; the 20 cells were divided equally to study delipidized and untreated SC: 3 cells each for MP and CP alone and 4 cells for mixtures of MP and CP. Two different subjects (identified as AP and AT) were studied.

\section{Chemical Analyses}

Solutions were analyzed for CP and MP using a Hewlett Packard 1100 series modular HPLC system with diode array detection (set at $254 \mathrm{~nm}$ ) equipped with a Zorbax Eclipse XDB-C18 analytical column (Hewlett Packard, $4.6 \mathrm{~mm} \times 25 \mathrm{~cm}$ ) and a guard column $(4.6 \times 12.5 \mathrm{~mm})$ with the same packing. The injection volume was $10 \mu \mathrm{l}$ and the mobile phase was pumped at $1.5 \mathrm{ml}$. $\mathrm{min}^{-1}$. Two different methods were used. In the analysis of the solutions from the skin experiments, the mobile phase was ramped from 30 to $40 \%$ HPLC grade acetonitrile in DI water over 4 min and then remained unchanged for 2 additional minutes. The retention times were 4.3 and $4.8 \mathrm{~min}$ for $\mathrm{CP}$ and $\mathrm{MP}$, respectively. For solutions from the SRM experiments, the mobile phase was ramped from 30 to $40 \%$ HPLC grade methanol in DI water over 4 min and then held for an additional $8.5 \mathrm{~min}$. The retention times were 6.9 and $10.6 \mathrm{~min}$ for $\mathrm{CP}$ and $\mathrm{MP}$, respectively.

\section{Calculated Quantities}

Flux through the skin $\left(J_{m}\right)$ was calculated for the sample interval $\left(t_{m}-t_{m-1}\right)$ as follows:

$$
J_{m}=q C_{m} / A
$$

where $A$ is the diffusion area of $0.64 \mathrm{~cm}^{2}$ and $C_{m}$ is the measured concentration of sample $m$ in the receptor solution collected from a cell with an average volumetric flow rate $q$. In graphs, $J_{m}$ is plotted at the midpoint of the sample interval $\left(t_{m}-t_{m-1}\right)$. Data points shown with error bars represent the mean value of all measurements made at each time plus or minus the $95 \%$ confidence interval. An estimate of the $J_{s s}$ for each cell was calculated as the average flux determined for the last 3 two-hour sampling intervals, 

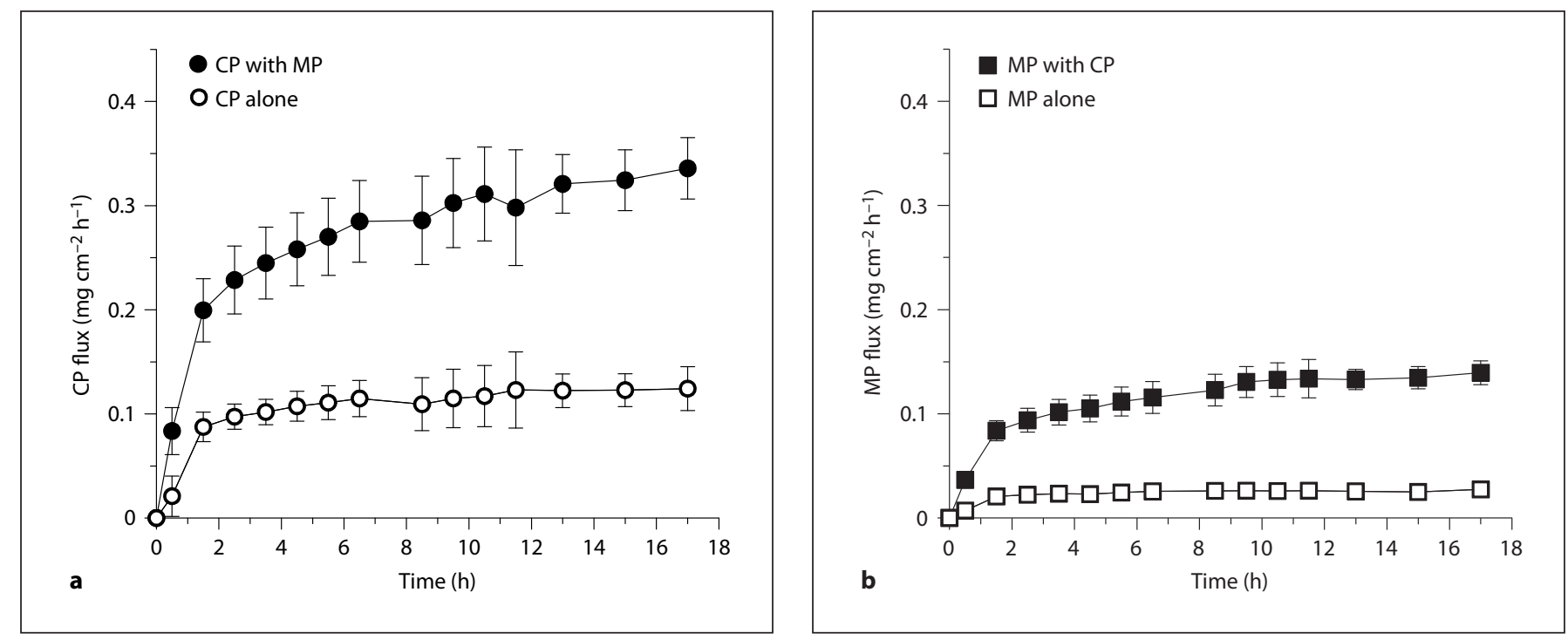

Fig. 2. Skin permeation results for $\mathrm{CP}$ and $\mathrm{MP}$ as a function of time.

which started at $12 \mathrm{~h}$ and ended at $18 \mathrm{~h}$. The concentration of either MP or CP per mass of dry untreated and delipidized SC that is equilibrated with a saturated solution [designated as $C_{s c \text {, sat }}$ and $\left(C_{s c, s a t}\right)_{d e l i p}$, respectively] were combined with the measured dry mass fraction of lipid extracted, $f_{\text {lip }}$, to estimate the concentration per dry mass of the lipid fraction in the $\mathrm{SC}\left(C_{s c, s a t}\right)_{l i p}$ as follows:

$$
\left(C_{s c, s a t}\right)_{l i p}=\left[C_{s c, s a t}-\left(1-f_{l i p}\right)\left(C_{s c, s a t}\right)_{d e l i p}\right] / f_{l i p}
$$

Unless noted otherwise, numerical values for flux and concentration are reported as the mean \pm the $95 \%$ confidence interval along with the number of measurements (designated by $n$ ). Statistical comparisons of means were carried out using a single-factor analysis of variance, in which the probability (p) that each sample group is drawn from the same underlying probability distribution was estimated. Comparisons were taken to be statistically significantly different if $\mathrm{p}$ was determined to be less than 0.05 .

\section{Results and Discussion}

The skin permeation results for $\mathrm{CP}$ and $\mathrm{MP}$ are shown as a function of time in figure 2. Steady-state estimates of the flux for $\mathrm{CP}$ and MP alone and in combination are listed in table 1 . The permeation rates of MP and CP are large, exceeding $10 \mu \mathrm{g} / \mathrm{cm}^{2} \cdot \mathrm{h}$. When measured without the other solute present, the fluxes of $\mathrm{CP}$ and $\mathrm{MP}$ observed in this study are consistent with previously published results [14-16]. The $J_{s s}$ through skin from 1 person, measured in vitro, was reported to be $0.168 \pm 0.033 \mathrm{mg} /$ $\mathrm{cm}^{2} \cdot \mathrm{h}$ (mean \pm 1 standard deviation, $\mathrm{n}=12$ ) for $\mathrm{CP}$ and $0.091 \pm 0.0097 \mathrm{mg} / \mathrm{cm}^{2} \cdot \mathrm{h}$ (mean \pm 1 standard devia- tion, $\mathrm{n}=9$ ) for MP [14]. In another study, the $J_{s s}$ for CP from a saturated aqueous solution was determined to be $0.086 \pm 0.021 \mathrm{mg} / \mathrm{cm}^{2} \cdot \mathrm{h}($ mean \pm 1 standard deviation $)$ in vivo in humans $(n=3)$ [15]. Also measured in vivo in humans, Stinchcomb et al. [16] reported the permeability coefficient for $\mathrm{CP}$ was $0.011 \pm 0.004 \mathrm{~cm} / \mathrm{h}$ (mean \pm 1 standard deviation), which when multiplied by the saturation concentration, $C_{\text {sat }}=18.4 \mathrm{mg} / \mathrm{ml}$, gives a $J_{s s}$ of $0.200 \pm 0.007 \mathrm{mg} / \mathrm{cm}^{2} \cdot \mathrm{h}$.

As shown in figure 2, permeation through skin from solutions with only CP or MP reached steady state within about $6 \mathrm{~h}$. The fluxes of both CP and MP from saturated solutions of the binary mixture were larger than from the single-solute solutions and continued to increase for a longer time. Compared to the single-solute solutions, the $J_{s s}$ was larger by more than 5 -fold for MP and by 2.6 -fold for CP.

The results for equilibrium uptake into a dry mass of isolated SC $\left(C_{s c, e q}\right)$ are listed in table 2 along with the concentrations of the solution in equilibrium with the SC $\left(C_{e q}\right)$ and the saturated solution $\left(C_{\text {sat }}\right)$. Values of the apparent partition coefficient between the SC and donor solution, calculated as the ratio of $C_{s c, e q}$ and $C_{e q}$, are also listed. Considering variability in the measurements, the result for $\mathrm{CP}$ alone $(15.5 \mathrm{ml} / \mathrm{g})$ is similar to $7.9 \mathrm{ml} / \mathrm{g}$ reported in a prior study $[9,17]$.

In the presence of MP, the saturation concentration of $\mathrm{CP}$ in water $\left(C_{\text {sat }}\right)$ increased only a little, while $C_{\text {sat }}$ for MP increased by almost a factor of 2 in the presence of $\mathrm{CP}$. 
Table 1. Concentration in the SC compared with flux through the SC from saturated aqueous solutions of MP and CP alone or in combination

\begin{tabular}{|c|c|c|c|c|c|c|c|c|}
\hline \multirow[t]{2}{*}{ Compound } & \multirow[t]{2}{*}{ Solution } & \multirow{2}{*}{$\begin{array}{l}C_{s c, s a t} \\
\mu \mathrm{g} / \mathrm{mg}\end{array}$} & \multicolumn{2}{|l|}{$\mathrm{n}$} & \multirow{2}{*}{$\begin{array}{l}J_{s s} \\
\mu \mathrm{g} / \mathrm{cm}^{2} \cdot \mathrm{h}\end{array}$} & \multirow{2}{*}{$\begin{array}{l}J_{s s} / C_{s c, s a t} \\
\mathrm{mg} / \mathrm{cm}^{2} \cdot \mathrm{h}\end{array}$} & \multirow[t]{2}{*}{$S R$} & \multirow[t]{2}{*}{$F R$} \\
\hline & & & $\mathrm{L}$ & Q & & & & \\
\hline \multirow[t]{2}{*}{ MP } & alone & $33.9 \pm 25 \%$ & 6 & 7 & $26.0 \pm 7.8 \%$ & $0.77 \pm 26 \%$ & & \\
\hline & with CP & $218 \pm 17 \%$ & 5 & 11 & $135 \pm 6.2 \%$ & $0.62 \pm 19 \%$ & $6.43 \pm 30 \%$ & $5.19 \pm 10 \%$ \\
\hline \multirow[t]{2}{*}{$\overline{\mathrm{CP}}$} & alone & $274 \pm 18 \%$ & 2 & 6 & $123 \pm 11 \%$ & $0.45 \pm 22 \%$ & & \\
\hline & with MP & $451 \pm 4.5 \%$ & 5 & 11 & $325 \pm 7.3 \%$ & $0.72 \pm 8.3 \%$ & $1.64 \pm 19 \%$ & $2.64 \pm 13 \%$ \\
\hline
\end{tabular}

Mean $\pm 95 \%$ confidence interval calculated using $\mathrm{n}$ as the total number of samples from subjects $\mathrm{L}$ and Q combined. All measurements were made at $32^{\circ} \mathrm{C}$.

$C_{s c, \text { sat }}$ : estimated amount of the compound in the SC per mass of dry SC that was equilibrated with a saturated solution; if the difference between $C_{e q}$ and $C_{s a t}$ was not statistically significant, then $C_{s c, s a t}=C_{s c, e q}$. If the difference between $C_{e q}$ and $C_{s a t}$ was statistically significant, then $C_{s c \text {, sat }}$ was estimated using equation (2) and the $95 \%$ confidence interval was calculated as the square root of the sum of the $95 \%$ confidence intervals squared for $C_{s c}, C_{e q}$ and $C_{s a t}$. If the SC is not changed by the presence of a second compound, then $C_{s c \text {, sat }}$ should be the same whether or not the other compound is present.

n: number of flux measurements made on skin samples from each subject.

$J_{s s}$ : steady-state flux estimated from 3 two-hour samples collected over the interval from 12 to $18 \mathrm{~h}$. If the SC is not changed by the presence of the other compound, $J_{s s}$ should be the same whether or not the other compound is present.

$J_{s s} / C_{s c, \text { sat }}:$ ratio of the mean values from $J_{s s}$ and $C_{s c, s a t}$; the $95 \%$ confidence interval was estimated as the square root of the sum of the $95 \%$ confidence intervals squared for $J_{s s}$ and $C_{s c \text {, sat }}$. If the ratio for the compound alone is not the same in the presence of the second compound, then the second compound changed the diffusive properties of the SC.

$S R$ : the saturation ratio $(S R)$ is the ratio of the mean values $C_{s c \text {, sat }}$ measured with and without the presence of the second compound.

FR: the flux ratio $(F R)$ is the ratio of the mean values of $J_{s s}$ measured with and without the presence of the second compound.

$S R$ and FR: the indicated 95\% confidence intervals were estimated as the square root of the sum of the $95 \%$ confidence intervals squared for the measurement with and without the presence of the second compound.

Table 2. Concentrations in the solutions and the SC from saturated aqueous solutions of MP and CP alone or in combination

\begin{tabular}{llllll}
\hline Compound & Solution & $C_{\text {eq }}, \mathrm{mg} / \mathrm{ml}$ & $C_{\text {sat }}, \mathrm{mg} / \mathrm{ml}$ & $C_{s c, e q}, \mu \mathrm{g} / \mathrm{mg}$ & $C_{s c, e q} / C_{e q}, \mathrm{ml} / \mathrm{g}$ \\
\hline \multirow{2}{*}{$\mathrm{MP}$} & alone & $3.15 \pm 2.8 \%$ & $3.11 \pm 49 \%(\mathrm{p}=0.65)$ & $33.9 \pm 25 \%$ & $10.7 \pm 23 \%$ \\
& with CP & $5.30 \pm 3.2 \%$ & $5.95 \pm 4.9 \%(\mathrm{p}=0.0036)$ & $194 \pm 16 \%$ & $36.5 \pm 14 \%$ \\
\hline $\mathrm{CP}$ & alone & $17.4 \pm 8.8 \%$ & $18.4 \pm 5.4 \%(\mathrm{p}=0.54)$ & $274 \pm 18 \%$ & $15.5 \pm 10 \%$ \\
& with MP & $20.0 \pm 2.5 \%$ & $20.9 \pm 44 \%(\mathrm{p}=0.12)^{\mathrm{a}}$ & $451 \pm 4.5 \%^{\mathrm{b}}$ & $22.6 \pm 3.0 \%{ }^{\mathrm{b}}$ \\
\hline
\end{tabular}

Mean $\pm 95 \%$ confidence interval. Unless indicated otherwise, the $95 \%$ confidence interval was calculated using $n=10$ ( 5 pieces of skin from each of the 2 subjects). All measurements were made at $32^{\circ} \mathrm{C}$.

$C_{e q}$ : concentration of the compound measured in the solution that had been equilibrated with the SC $\left(C_{e q}\right)$. For both MP and $\mathrm{CP}$, $C_{e q}$ values for the compound alone and in the presence of the other compound are statistically significantly different $(\mathrm{p}<0.002$ with a $95 \%$ confidence).

$C_{\text {sat }}$ : concentration of the compound measured in the saturated stock solution $\left(C_{s a t}\right)$ determined in duplicate; the listed $\mathrm{p}$ values indicate the probability that the values of $C_{s a t}$ and $C_{e q}$ are statistically the same with a $95 \%$ level of confidence.

$C_{s c, e q}$ : amount of the compound in the SC per mass of dry SC that was equilibrated in an initially saturated solution.

$C_{s c, e q} / C_{e q}$ : the ratio of $C_{s c, e q}$ to $C_{e q}$ (i.e. the apparent partition coefficient between the SC and water) was determined in each cell and then averaged over all cells.

${ }^{\text {a }}$ Not statistically different from $C_{\text {sat }}$ for CP alone ( $\mathrm{p}=0.075$ with $95 \%$ confidence).

${ }^{\mathrm{b}} \mathrm{n}=4$ for subject $\mathrm{Q}$. 
Thus, adding MP to a solution of CP appears to have almost no effect on the thermodynamic activity of CP. However, adding CP (at least in the large amounts studied here) to a solution of MP at constant concentration changes the thermodynamic activity of MP. Nevertheless, because the solutions in this study were all saturated, the thermodynamic activity of each solute should be the same with and without the other compound present, since both $\mathrm{CP}$ and $\mathrm{MP}$ are in equilibrium with their pure solids.

As observed in the permeation measurements, the equilibrium uptake of both MP and CP into the SC $\left(C_{s c, s a t}\right)$ increased significantly in the presence of the other compound, as did the apparent equilibrium partition coefficient (table 2). In comparing $C_{e q}$ with $C_{s a t}$, only the concentration of MP in the presence of $\mathrm{CP}$ was significantly reduced by uptake into the $\mathrm{SC}$; therefore, $C_{s c \text {, sat }}$ for $\mathrm{MP}$ in the presence of $\mathrm{CP}$ was estimated using equation (2). For MP alone and for $\mathrm{CP}$ alone and with MP, $C_{s c, \text { sat }}$ was assumed to equal $C_{s c \text {, eq. }}$. Like the flux numbers, the values for $C_{s c, s a t}$, which are also listed in table 1, are large, ranging from 0.03 (for MP alone) to $0.45 \mathrm{mg}$ (for $\mathrm{CP}$ in the presence of MP) of solute per milligram of dry SC. In the presence of the saturated solution containing both $\mathrm{MP}$ and $\mathrm{CP}$, there is $0.76 \mathrm{mg}$ of chemical (MP and CP combined) in each milligram of dry SC.

Assuming $3.7 \mathrm{ml}$ of hydrated SC per gram of dry SC [9], the saturation uptake numbers listed in table 1 (i.e. $\left.C_{s a t, s c}\right)$ correspond to 9.16 and $58.9 \mathrm{mg}$ of MP per milliliter of hydrated SC with and without $\mathrm{CP}$, respectively, and to 74.1 and $121 \mathrm{mg}$ of CP per milliliter of hydrated SC with and without MP, respectively. Based on hydrated SC, the equilibrium partition coefficients for MP and $\mathrm{CP}$ are respectively 2.9 and 4.2 , when measured from single-solute solutions; for the mixed MP and CP solutions, these increase to 9.9 and 6.1 for MP and CP, respectively. These numbers are reasonable in value when compared with measurements of other solutes of similar size and lipophilic character [9].

Examining the $C_{s c \text {, sat }}$ values listed in table 1 further, we see that the uptake of $\mathrm{CP}$ from a saturated solution increased by a factor (i.e. the saturation ratio, $S R$ ) of about 1.6 when MP was present at saturation, while the uptake of MP increased by more than 6-fold when CP was present at saturation. It is also interesting that the uptake of $\mathrm{CP}$ is 8.1 times larger than $\mathrm{MP}$ when each is present alone, and that the uptake ratio of $\mathrm{CP}$ to MP decreases to 2.1 when both compounds are present in saturation. Although $C_{\text {sat }}$ for MP and CP are different in solutions containing 1 or both solutes, the thermodynamic activity
Table 3. Steady-state flux through the silicone SRM from saturated aqueous solutions of MP and CP alone or in combination

\begin{tabular}{lllll}
\hline Compound & Solution & $\mathrm{n}$ & $J_{s s}, \mu \mathrm{g} / \mathrm{cm}^{2} \cdot \mathrm{h}$ & $F R$ \\
\hline MP & alone & 4 & $48.9 \pm 12.3 \%$ & \\
& with CP & 6 & $51.3 \pm 4.3 \%$ & $1.05 \pm 13 \%$ \\
$\mathrm{CP}$ & alone & 4 & $91.4 \pm 6.0 \%$ & \\
& with MP & 6 & $96.8 \pm 6.0 \%$ & $1.06 \pm 8.5 \%$ \\
\hline
\end{tabular}

$J_{s s}:$ mean $\pm 95 \%$ confidence interval for the indicated number of replicates (n). All measurements were made at $32^{\circ} \mathrm{C}$. There was no statistically significant difference in the flux for either solute alone or in combination with the other.

FR: ratio of the steady-state fluxes from the binary solute solution to the single solute solution. The indicated $95 \%$ confidence intervals were estimated as the square root of the sum of the $95 \%$ confidence intervals squared for the measurement with and without the presence of the second compound.

does not change and $C_{s c \text {, sat }}$ should be constant if the SC was not changed by the presence of the second solute. It is evident, therefore, that the solubility of MP and CP in the SC each increase in the presence of the second solute.

Changes in diffusivity can be discerned by examining the ratio of the flux and uptake as described by equation (1). For MP, the ratio of $J_{s s}$ to $C_{s c \text {, sat }}$ is not significantly different when CP is or is not present. Thus, in the presence of $\mathrm{CP}$, the MP permeation rate rises proportionally to the increase in $C_{s a t, s c}$ suggesting that $\mathrm{CP}$ primarily changes the solubility but not the diffusivity of MP in the SC. Like the effect of CP on MP permeation, Herkenne et al. [18] observed that propylene glycol increased ibuprofen permeation by enhancing its solubility without changing its diffusivity. In contrast, the permeation of CP in the presence of MP is 1.6-fold larger than would be expected based on the increase in $C_{s a t, s c}$ alone. This suggests that the diffusive component of $\mathrm{CP}$ penetration through the $\mathrm{SC}$ is increased by the presence of MP. Stated differently, the flux ratio (FR) with and without the second compound compared to the $S R$ is not statistically different for MP but is different for CP.

Comparing the values $J_{s s} / C_{s c \text {, sat }}$ for MP and CP, it appears that the diffusivity for MP alone and in the presence of saturated CP solutions are almost the same as the diffusion rates for $\mathrm{CP}$ in the presence of saturated $\mathrm{MP}$ solutions. However, the diffusivity of $\mathrm{CP}$ alone appears to be about $40 \%$ smaller than for MP alone. The mechanism of this difference is not evident but might be ascertained by further experiments using differential scanning calo- 
Table 4. Equilibrium concentrations measured in untreated and delipidized SC from saturated aqueous solutions of MP and CP alone or in combination

\begin{tabular}{|c|c|c|c|c|c|c|c|c|c|c|}
\hline \multirow[t]{2}{*}{ Solution } & \multirow[t]{2}{*}{$C_{s a t}$} & \multirow{2}{*}{$\begin{array}{l}C_{s c, \text { sat }} \\
\text { untreated }\end{array}$} & \multirow{2}{*}{$\begin{array}{l}\left(C_{s c, \text { sat }}\right)_{\text {delip }} \\
\text { delipidized }\end{array}$} & \multirow{2}{*}{$\begin{array}{l}\left(C_{s c, s a t}\right)_{l i p} \\
\text { lipids }\end{array}$} & \multirow[t]{2}{*}{$f_{\text {lip }}$} & \multicolumn{3}{|l|}{$S R$} & \multirow{2}{*}{$\begin{array}{l}\left(C_{s c, \text { sat }}\right)_{\text {delip }} / \\
C_{s c, \text { sat }}\end{array}$} & \multirow{2}{*}{$\begin{array}{l}\left(C_{s c, \text { sat }}\right)_{\text {lip }} / \\
\left(C_{s c, \text { sat }}\right)_{\text {delip }}\end{array}$} \\
\hline & & & & & & untreate & delipidized & lipids & & \\
\hline \multicolumn{11}{|l|}{ MP } \\
\hline Alone & $3.02 \pm 7.9 \%$ & $22.9 \pm 27 \%$ & $12.1 \pm 17 \%^{\mathrm{a}}$ & 69 & $0.19 \pm 17 \%$ & & & & 0.53 & 5.7 \\
\hline With CP & $5.13 \pm 2.0 \%$ & $120 \pm 25 \%$ & $104 \pm 12 \%$ & 187 & $0.20 \pm 22 \%$ & 5.25 & 8.57 & 2.71 & 0.87 & 1.8 \\
\hline \multicolumn{11}{|l|}{ CP } \\
\hline Alone & $17.5 \pm 2.9 \%$ & $160 \pm 24 \%$ & $123 \pm 9.0 \% \%^{\mathrm{a}}$ & 308 & $0.20 \pm 32 \%$ & & & & 0.77 & 2.5 \\
\hline With MP & $19.8 \pm 1.8 \%$ & $268 \pm 29 \%$ & $209 \pm 11 \%$ & 508 & $0.20 \pm 22 \%$ & 1.68 & 1.71 & 1.65 & 0.78 & 2.4 \\
\hline
\end{tabular}

Mean \pm 1 standard deviation (percent of mean). All measurements were made at $32^{\circ} \mathrm{C}$.

$C_{\text {sat }}$ : concentration (milligrams/milliliter) of the compound in the saturated solution equilibrated with the SC $\left(C_{\text {sat }}\right)$ measured in the untreated and delipidized SC experiments combined $(\mathrm{n}=12$ for MP and CP alone and $\mathrm{n}=14$ for the MP-CP mixtures). For both MP and CP, the differences in the $C_{\text {sat }}$ values for each compound alone and in the presence of the other compound are highly statistically significant $(\mathrm{p}<0.001)$

$C_{s c, \text { sat }},\left(C_{s c \text {, sat }}\right)_{\text {delip}},\left(C_{s c, s a t}\right)_{l i p}$ : amount of the compound in the SC per mass of dry SC (micrograms/milligram) that was equilibrated in a saturated solution of the designated compound(s) for SC samples that are untreated $\left(C_{s c, s a t}\right)$ or delipidized $\left(C_{s c \text {, sat }}\right)_{\text {delip. }}$. The amount in the lipid fraction of the SC $\left(C_{s c, \text { sat }}\right)_{\text {lip }}$ is estimated from the saturation concentration measured in the untreated and delipidized SC as specified in equation (4). For solutions of either MP or $\mathrm{CP}$ alone, $\mathrm{n}=3$ for each of the 2 subjects (AP and AT) except for $\mathrm{MP}$ in subject $\mathrm{AT}$, for which $\mathrm{n}=2$. For solutions of $\mathrm{MP}$ and $\mathrm{CP}$ combined, $\mathrm{n}=4$ for each of the 2 subjects (AP and AT). For both $\mathrm{MP}$ and $\mathrm{CP}$, the difference in $C_{s c \text {, sat }}$ values for untreated and delipidized SC for each compound alone and in the presence of the other are statistically significant $(p<0.01)$.

$f_{\text {lip }}$ : mass fraction of lipid removed from the delipidized SC $\left(f_{\text {lip }}\right)$ calculated from gravimetric determinations before and after the delipidizing treatment for SC samples used in experiments for each solution. For all samples from each subject, $f_{\text {lip }}$ in subject AP $(0.16 \pm 6.8 \%)$ was statistically significantly different from $f_{\text {lip }}$ in subject AT $(0.23 \pm 12 \%)(\mathrm{p}<0.001)$. For all samples from both subjects, $f_{\text {lip }}$ was $0.19 \pm 23 \%$.

$S R$ : the $S R$ of the saturation concentration in the SC when the second compound is and is not present in the SC that is untreated $\left(C_{s c, s a t}\right)$ or delipidized, $\left(C_{s c, \text { sat }}\right)_{\text {delip }}$, or is estimated to be in the lipid fraction of the SC lipids $\left(C_{s c, s a t}\right)_{l i p}(\mathrm{p}<0.05)$.

a The measured $\left(C_{s c, s a t}\right)_{\text {delip }}$ is statistically significantly different from $C_{s c, \text { sat }}(\mathrm{p}<0.005$ for MP and $\mathrm{p}<0.05$ for $\mathrm{CP})$. rimetry, Fourier transform infrared spectroscopy or Raman spectroscopy.

Since the thermodynamic activities of MP and CP in saturated solutions should be the same whether or not the other solute is present, the saturated flux of MP and CP through a membrane that is unchanged by $\mathrm{MP}$ and $\mathrm{CP}$ should be the same whether or not the other solute is present. This hypothesis was tested on SRM, which should not be changed by either MP or CP. As shown in table 3, there was no statistically significant difference in the saturated flux through SRM by MP or CP when they were present alone or in combination. Permeations of MP (48.2 $\left.\pm 2.5 \mu \mathrm{g} / \mathrm{cm}^{2} \cdot \mathrm{h}, \mathrm{n}=6\right)$ and CP $\left(78.9 \pm 6.4 \mu \mathrm{g} / \mathrm{cm}^{2} \cdot \mathrm{h}\right.$, $\mathrm{n}=7$ ) from saturated solutions of the single solute had also been measured in a prior study (reported as mean \pm 1 standard deviation) [14]. Compared with our findings, the results from the prior study are nearly identical for MP and lower by a small but statistically significant difference for CP. The most likely cause of this variation for $\mathrm{CP}$ is a difference in temperature control of the diffusion cells in the 2 studies. In the prior study [14], diffusion cell temperatures were controlled at $37^{\circ} \mathrm{C}$ with no temperature control of the donor solution in a room at about $23^{\circ} \mathrm{C}$. In this study, the entire cell, including the donor solution, was controlled at $32^{\circ} \mathrm{C}$.

To assess the contribution of the lipid and nonlipoidal components of the SC on uptake, we compared measurements of the saturated uptake concentration into delipidized and untreated SC. The results, listed in table 4, indicate that the saturated uptake concentration of $\mathrm{CP}$ into SC without lipids is about $80 \%$ of SC with lipids. A similar result was observed for MP in the presence of $\mathrm{CP}$. However, when MP is present alone, the uptake into SC without lipids was only about $50 \%$ of SC with lipids. This suggests that $\mathrm{CP}$ enhances MP uptake primarily by increasing the amount of MP in the fraction that is left by the delipidizing treatment (i.e. in the corneocytes). In contrast, the ratio of CP uptake into SC equilibrated in solutions with and without MP is essentially the same for the untreated and delipidized SC (i.e. 1.68 and 1.71, re- 
spectively). Consistent with the hypothesis that $\mathrm{CP}$ increases MP solubility in the corneocytes, the ratio of MP concentrations in the lipid and delipidized SC fractions decreased by a factor of more than 3 (i.e. from 5.7 to 1.8) when $\mathrm{CP}$ was added. For $\mathrm{CP}$, this ratio was essentially unchanged when MP was added (i.e. 2.5 and 2.4, respectively).

Comparing the untreated SC results listed in tables 1 and 2, subject-to-subject variation is evident. However, the variation between subjects is much less for the ratio of uptake measured with and without the second compound. For example, MP uptake increased in the presence of CP by factors of 6.4 (table 1) compared with 5.3 (table 4); CP uptake was increased by MP with ratios of 1.64 (table 1) compared with 1.68 (table 4).

The mechanism by which CP increases MP solubility in the delipidized SC is unknown, as is the way in which MP increases the diffusion and solubility of CP. Certainly, CP solubility in water and also the SC are large; one can imagine that MP solubility could be increased in corneocytes containing large amounts of CP. Effects such as changes in protein conformation or lipid fluidization have been assessed using Fourier transform infrared spectroscopy and differential scanning calorimetry; e.g. see [19]. The effect of lipid fluidization, if it occurs, is likely to be small. The increased diffusion and uptake of $\mathrm{CP}$ in the presence of MP is modest. As for MP, CP appears to enhance permeation primarily by increasing uptake in the delipidized fraction of the SC. There is little evidence that increased uptake and permeation of MP in the presence of $\mathrm{CP}$ is due to the lipids. It would be interesting to determine if $\mathrm{CP}$ changes the protein conformation of the SC and if this is related to increased MP uptake in the delipidized SC. To properly assess this question, Fourier transform infrared spectroscopy measurements and MP saturated uptake would need to be measured as a function of CP concentration. This investigation has been left for a future study.

In this study, MP and CP were selected as model compounds because of similarities in their physicochemical resemblance, which might, therefore, cause permeation to be affected by the other, their facile chemical analysis and their previous measurements. Given that parabens in general and MP in particular are common additives to many products applied topically to skin or that will have skin contact (e.g. food and consumer products), these results suggest that MP permeation might be increased by formulation components that have similar physicochemical properties to CP. The significance of this in terms of human health risk from exposure to MP is likely to be small, however, due to the relatively low toxicity and generally small concentrations of MP. Nevertheless, this study shows that permeation enhancement remains largely unpredictable, and thus, dermal toxicity predictions derived from measurements of single solutes might underestimate the toxicity of chemicals in mixtures.

The approach for assessing the mechanism of enhanced or retarded permeation for MP and CP was also applied to previously reported measurements of saturated aqueous solutions of MP, ethyl paraben (EP), propel paraben and butyl paraben (BP) in the absence and presence of NA [20]. The experimental details are provided in the original paper. Briefly, the cumulative amount that permeated through rabbit skin over $7 \mathrm{~h}$ was measured in static diffusion cells, with the receptor phase solution thermostatted at $37^{\circ} \mathrm{C}$. Diffusion and partitioning parameters $\left(D / h^{2}\right.$ and $K \cdot h$, respectively) were calculated by regressing the data to the theoretical equation describing cumulative mass versus time written for Fickian diffusion through an initially solute-free, single homogeneous membrane at local equilibrium on the donor side and with sink conditions on the receptor side. The calculated partitioning parameter is the product of the diffusion path length $(h)$ and the skin-donor solution partition coefficient $(K)$. The solubility parameter $\left(h C_{e q, s c} \rho_{s c}\right)$ in equation (1) is equal to the product of $(K \cdot h)$ and the saturated paraben concentration in the donor solution (i.e. $C_{\text {sat }}$ ).

The results for each of the 4 parabens are listed in table 5 for $C_{\text {sat }}$ and the ratios of measurements from solutions with and without added NA $(20 \% \mathrm{w} / \mathrm{v})$ for 4 quantities: $C_{s a t},\left(h C_{e q, s c} \rho_{s c}\right), J_{s s}$, and $J_{s s} /\left(h C_{e q, s c} \rho_{s c}\right)$. In the presence of NA, $C_{\text {sat }}$ increased by more than 10 -fold except for EP, which showed only a 2 -fold increase. The authors found that the unusual saturation behavior of EP in solutions of NA was attributable to formation of a cocrystal having a 1:1 molar composition [20,21]. As a consequence, the thermodynamic activity of EP in the saturated solution would not be the same with and without added NA.

As indicated by values of $F R$ in table 5 , in the presence of NA the permeation of MP is essentially unchanged, and the $J_{s s}$ of PP and BP are enhanced primarily by significant increases in the SC uptake. The flux of EP is retarded by NA, most probably because the thermodynamic activity of EP in the saturated solution with NA present is smaller than the thermodynamic activity of EP in the saturated EP solution when NA is absent. Within the variability of the measurements, NA has no significant effect on the skin diffusion rates for the 3 smaller parabens but perhaps a small enhancement for BP (see values 
Table 5. The effect of $20 \% \mathrm{w} / \mathrm{v}$ NA on the saturation concentrations in water and the SC, and on the steady-state flux and diffusion through skin from saturated solutions for 4 parabens

\begin{tabular}{|c|c|c|c|c|c|}
\hline Compound & $C_{s a t}, \mathrm{mg} / \mathrm{ml}$ & $\left(C_{s a t}\right)_{N A} / C_{s a t}$ & $S R$ & $F R$ & $F R / S R$ \\
\hline MP & $2.13 \pm 0.12$ & 12.1 & 1.33 & 1.19 & 0.89 \\
\hline $\mathrm{EP}^{\mathrm{a}}$ & $1.16 \pm 0.21$ & 2.1 & 0.483 & 0.410 & 0.85 \\
\hline PP & $0.37 \pm 0.03$ & 22.1 & 3.76 & 2.60 & 0.69 \\
\hline $\mathrm{BP}$ & $0.158 \pm 0.014$ & 31.0 & 2.48 & 2.82 & 1.14 \\
\hline
\end{tabular}

From Nicoli et al. [20].

$C_{\text {sat }}$ : saturation concentration of the compound in distilled water at $25^{\circ} \mathrm{C}$ reported as mean \pm 1 standard deviation (information provided by personal communication from S. Nicoli, January 2009).

$S R$ : SC saturation ratio, which is equal to the ratio of concentrations in SC equilibrated with saturated solutions of a paraben with $\left(C_{e q, s c} h \rho_{s c}\right)_{N A}$ and without $\left(C_{e q, s c} h \rho_{s c}\right)$ added $N A ; S R=\left(C_{e q, s c}\right.$ $\left.h \rho_{s c}\right)_{N A} /\left(C_{e q, s c} h \rho_{s c}\right)$. In the notation of the original paper, $S R=$ $\left(K H_{\mathrm{NA}}: K H_{\mathrm{W}}\right) \cdot\left(S_{\mathrm{NA}}: \mathrm{S}_{\mathrm{W}}\right)$, where $K$ is the hydrated SC-to-water partition coefficient, $H$ is the diffusion path length (i.e. $h$ in the notation of this paper) and $S$ is the saturation concentration of paraben in the solution (i.e. $C_{s a t}$ in the notation of this paper).
FR: flux ratio, which is equal to the state-state fluxes through previously frozen rabbit ear skin from saturated solutions of a paraben with $\left(J_{s s}\right)_{N A}$ and without $\left(J_{s s}\right)$ added $N A ; F R=\left(J_{s s}\right)_{N A} /\left(J_{s s}\right)$. In the notation of the original paper, $F R=\left(P_{\mathrm{NA}}: P_{\mathrm{W}}\right) \cdot\left(S_{\mathrm{NA}}: S_{\mathrm{W}}\right)$, where $P_{\mathrm{NA}}$ and $P_{\mathrm{W}}$ are the permeability coefficients measured through skin when NA is and is not present, respectively, and $S$ is the saturation concentration of paraben in the solution (i.e. $C_{s a t}$ in the notation of this paper).

$F R / S R$ : the ratio of $F R$ to $S R$ should indicate the effective diffusivities of the paraben in the SC from saturated solutions of a paraben with and without added NA.

${ }^{\text {a }}$ EP has been shown to form a 1:1 cocrystal with NA [21]. As a consequence, the thermodynamic activity of EP is most probably not the same in the EP saturated solutions that do and do not include NA.
Table 6. The effect of $20 \% \mathrm{w} / \mathrm{v}$ NA on the IPM-water partition coefficient and estimates of the saturation concentration in IPM for 4 parabens

\begin{tabular}{lccccl}
\hline Compound & $\log K_{\text {oct } / \mathrm{w}}{ }^{\mathrm{a}}$ & $K_{I P M / w}$ & $\left(K_{I P M / w}\right)_{N A}$ & $K_{I P M / w} /\left(K_{I P M / w}\right)_{N A}$ & $\left(C_{\text {sat, IPM }}\right)_{N A} / C_{\text {sat, IPM }} \mathrm{b}$ \\
\hline $\mathrm{MP}$ & 1.93 & 91.2 & 5.37 & 17.0 & 0.71 \\
$\mathrm{EP}$ & 2.27 & 186 & 12.9 & 14.5 & 0.15 \\
$\mathrm{PP}$ & 2.81 & 501 & 75.9 & 6.61 & 3.34 \\
$\mathrm{BP}$ & 3.57 & 1,350 & 170 & 7.95 & 3.90 \\
\hline
\end{tabular}

Nicoli et al. [20] present IPM-water partition coefficients in figure 6. The numerical values listed here were provided by S. Nicoli (personal communication, 22 January 2009).

${ }^{\text {a }}$ Logarithm of the octanol-water partition coefficient values listed in the original paper [20].

${ }^{b}$ Ratios of the estimated saturation concentrations for IPM with and without NA present were calculated using equation (5).

${ }^{\mathrm{c}}$ EP has been shown to form a 1:1 cocrystal with NA [21]. As a consequence, the thermodynamic activity of EP is most probably not the same in the solution with and without added NA. of $F R / S R$ in table 5). Except for EP, $\mathrm{SC}$ in equilibrium with the solution containing NA can hold more paraben than expected (as indicated by the SC SR in table 5) based on the increase in the aqueous saturation concentration.

The authors of the paraben and NA study also measured partition coefficients between isopropyl myristate $(\mathrm{IPM})$ and distilled water with $\left(K_{I P M / w}\right)_{N A}$ and without
$\left(K_{I P M / w}\right)$ adding NA $(20 \% \mathrm{w} / \mathrm{v})$. These partitioning experiments were carried out at concentrations less than saturation. The results are listed in table 6 along with values of the octanol-water partition coefficients. Because the presence of NA increases the paraben saturation concentration in water, the ratio of $\left(K_{I P M / w}\right)$ to $\left(K_{I P M / w}\right)_{N A}$ is larger than 1. An estimate for the paraben saturation concen- 
tration in IPM that is in the presence $\left(C_{s a t, I P M}\right)_{N A}$ and absence of NA $\left(C_{\text {sat, IPM }}\right)$ can be derived by comparing ratios with and without NA for the IPM-water partition coefficient and the paraben saturation concentration as follows:

$$
\frac{\left(C_{s a t, I P M}\right)_{N A}}{C_{s a t, I P M}} \approx \frac{\left(C_{s a t}\right)_{N A}}{C_{s a t}} / \frac{K_{I P M / w}}{\left(K_{I P M / w}\right)_{N A}}=\frac{\left(C_{\text {sat }}\right)_{N A}}{C_{s a t}} \frac{\left(C_{e q, I P M} / C_{e q}\right)_{N A}}{C_{e q, I P M} / C_{e q}}
$$

where $C_{e q, I P M}$ is the paraben concentration in the IPM that was equilibrated with water. If the thermodynamic activity of the paraben is the same in the saturated aqueous solutions with and without NA present, then differences in $\left(C_{s a t, I P M}\right)_{N A}$ compared with $C_{s a t, I P M}$ indicate that the presence of NA has changed the IPM.

As shown in table 6, $\left(C_{s a t, I P M}\right)_{N A}$ is similar to $C_{s a t, I P M}$ for MP but significantly larger than $C_{\text {sat, IPM }}$ for PP and BP. In other words, in the presence of NA, $C_{s a t, I P M}$ for PP and $\mathrm{BP}$ increased by more than would be expected based on the increase in the water saturation concentrations alone. For EP the estimated ratio for $\left(C_{s a t, I P M}\right)_{N A}$ to $C_{\text {sat, IPM }}$ is much smaller than 1 . This probably occurs because the IPM-water partition coefficient measurements were made at concentrations less than the saturation concentration. As a result, the EP-NA cocrystal was not present and the thermodynamic activity of the EP in the equilibrated IPM and water solutions might have been more like the other paraben solutions that do not form a solid phase with NA. If this happens, then the increase in EP water solubility in the presence of NA might be a number between the ratio for MP (12.1) and PP (22.1) rather than the measured value of 2.1. For example, if the ratio was 15 , then $\left(C_{\text {sat, IPM }}\right)_{N A} / C_{\text {sat, IPM }}$ is estimated to be 1 , indicating that, in the presence of NA, the saturation concentration in IPM increased by the same ratio as the saturation concentration in water.

Finally, we compare the ratio of the estimated IPM saturation concentrations to that of the saturation concentration in the SC with and without NA (see the values of $S R$ in table 5). Consistent with the suggestions that IPM is a suitable surrogate for SC uptake [22], except for EP, the estimated IPM saturation concentrations do roughly represent the effects of NA on paraben uptake by the SC.

\section{Conclusions}

Although there is nothing in the chemical structures of MP or CP suggesting that either would be a penetration enhancer (other than their similarities to each other), the dermal permeation rates as well as SC uptake for both compounds are increased when the other is present. The increase in MP flux in the presence of $\mathrm{CP}$ is primarily due to rises in MP uptake in the SC, whereas the increase in $\mathrm{CP}$ flux in the presence of MP is due to changes in both the CP uptake as well as diffusion rates. It is apparent from measurements in delipidized compared with untreated SC that CP increases the uptake of MP primarily by enhancing the uptake into the corneocytes (i.e. the delipidized SC). In contrast, MP increases CP uptake in the lipids and corneocytes equally. Finally, the diffusion rates for MP alone and in the presence of saturated CP solutions are almost the same as those for $\mathrm{CP}$ in the presence of MP. The application of this approach to diffusion cell data for MP and ethyl, propyl and BP showed that the addition of NA to saturated solutions of the parabens increased the paraben permeation through skin primarily by enhancing the SC uptake. The exception was EP, which, due to formation of a cocrystal with NA having a 1:1 molar composition, showed reduced skin uptake and flux in the presence of NA.

\section{Acknowledgements}

We acknowledge support from the United States Environmental Protection Agency (award No. R829518-01) and the National Institute of Occupational Safety and Health (application No. 1R01-OH007493-01A2). The authors express appreciation to E. White for his comments and S. Nicoli for providing data from the study of parabens and NA mixtures.

References Allan G: Mechanisms of action of skin penetration enhancers/retarders: Azone and analogues. Int J Pharm 1996;141:17-25.

2 Barry BW, Harrison SM, Dugard PH: Vapour and liquid diffusion of model penetrants through human skin; correlation with thermodynamic activity. J Pharm Pharmacol 1985;37:226-235.

3 Barry BW, Harrison SM, Dugard PH: Correlation of thermodynamic activity and vapour diffusion through human skin for the model compound, benzyl alcohol. J Pharm Pharmacol 1985;37:84-90.

4 Theeuwes F, Gale R, Baker R: Transference: a comprehensive parameter governing permeation of solutes through membranes. J Membr Sci 1976;1:3-16.

5 Twist JN, Zatz JL: Influence of solvents on paraben permeation through idealized skin model membranes. J Soc Cosmet Chem 1986;37:429-444. 
6 Kurihara-Bergstrom T, Flynn GL, Higuchi WI: Physicochemical study of percutaneous absorption enhancement by dimethyl sulfoxide: kinetic and thermodynamic determinants of dimethyl sulfoxide mediated mass transfer of alkanols. J Pharm Sci 1986;75: 479-486.

7 Thong HY, Zhai H, Maibach HI: Percutaneous penetration enhancers: an overview. Skin Pharmacol Physiol 2007;20:272-282.

8 Bunge AL: Why skin permeation data from neat and aqueous solutions of 2-butoxyethanol are not surprising; in Brain KR, Walters KA (eds): Perspectives in Percutaneous Penetration (PPP). La Grande Motte, STS Publishing, 2006.

9 Vecchia BE, Bunge AL: Partitioning of chemicals into skin: results and prediction; in Hadgraft J, Guy RH (eds): Transdermal Drug Delivery Systems. New York, Dekker, 2002, pp 143-198.

10 Syracuse Research Corporation: PhysProp Database. http://www.syrres.com/esc/physdemo.htm.
11 Peck KD, Ghanem AH, Higuchi WI, Srinivasan V: Improved stability of the human epidermal membrane during successive permeability experiments. Int J Pharm 1993;98: 141-147.

12 Liron Z, Wright RW, McDougal JN: Water diffusivity in porcine stratum corneum measured by a thermal graivemetric analysis (TGA) technique. J Pharm Sci 1994;83:457462.

13 Liron Z, Wright RW, McDougal JN: A mathematical model for water vapor sorption kinetics in porcine stratum corneum. J Pharm Sci 1994;83:692-698.

14 Romonchuk WJ, Bunge AL: Permeation of 4-cyanophenol and methyl paraben from powder and saturated aqueous solution through silicone rubber membranes and human skin. J Pharm Sci 2006;95:2526-2533.

15 Pirot F, Kalia YN, Stinchcomb AL, Keating G, Bunge A, Guy RH: Characterization of the permeability barrier of human skin in vivo. Proc Natl Acad Sci USA 1997;94:1562-1567.

-16 Stinchcomb AL, Pirot F, Touraille GD, Bunge AL, Guy RH: Chemical uptake into human stratum corneum in vivo from volatile and non-volatile solvents. Pharm Res 1999;16: 1288-1293.
17 Surber C, Wilhelm KP, Maibach HI, Hall LL, Guy RH: Partitioning of chemicals into human stratum corneum: implications for risk assessment following dermal exposure. Fundam Appl Toxicol 1990;15:99-107.

18 Herkenne C, Naik A, Kalia YN, Hadgraft J, Guy RH: Effect of propylene glycol on ibuprofen absorption into human skin in vivo. J Pharm Sci 2008;97:185-197.

19 Kim YC, Park JH, Ludovice PJ, Prausnitz MR: Synergistic enhancement of skin permeability by $\mathrm{N}$-lauroylsarcosine and ethanol. Int J Pharm 2008;352:129-138.

$>20$ Nicoli S, Zani F, Bilzi S, Bettini R, Santi P: Association of nicotinamide with parabens: effect on solubility, partition and transdermal permeation. Eur J Pharm Biopharm 2008;69:613-621.

21 Nicoli S, Bilzi S, Santi P, Caira MR, Li J, Bettini R: Ethyl-paraben and nicotinamide mixtures: apparent solubility, thermal behavior and X-ray structure of the 1:1 co-crystal. J Pharm Sci 2008;97:4830-4839.

22 Surber C, Wilhelm KP, Hori M, Maibach HI, Guy RH: Optimization of topical therapy: partitioning of drugs into stratum corneum. Pharm Res 1990;7:1320-1324. 